\title{
Pliny the Elder on Gilding
}

\section{A NEW INTERPRETATION OF HIS COMMENTS}

\author{
Ottavio Vittori \\ Institute of Physics, University of Bologna, Italy
}

\begin{abstract}
The description in Pliny's 'Natural History' of gilding bronze by using mercury becomes clearer if it is seen as a process in which mercury is used only as an adhesive for the gold leaf and in which it is not necessary to heat the object after gilding to drive off the excess mercury as is the case in the more usual fire- or mercury-gilding. Laboratory experiments on the techniques of gilding and a study of the older literature support this new interpretation and emphasise the importance of the purity of the substrate metal.
\end{abstract}

Features revealed in a study of the surface characteristics of the Golden Horses on St. Mark's basilica in Venice (1) have led to an investigation in detail of the gilding techniques used in antiquity. The unusual composition of the horses, which are practically pure copper, implies that they must have been difficult to cast. The choice of such a material appears more logical, however, in the light of results published by Craddock (2). This author suggests that the use of pure copper for some gilded artefacts of the classical age is the result of difficulties encountered by the ancient craftsmen in mercury-gilding substrates made of lead- or tin-rich copper alloys and he quotes Theophilus in support of this interpretation. Craddock's work as well as other recent researches concerning ancient gilt bronzes (3), provide the basis for a reassessment of Pliny's statements on gilding.

\section{Pliny's Texts on Gilding}

Pliny's 'Naturalis Historia' is one of the richest sources of technological information to have survived from Roman classical times. The vicissitudes to which the manuscripts were exposed through the centuries explain the difficulties now encountered by investigators in interpreting some of their contents. Furthermore, Pliny may have been inaccurate in regard to some technical terms (4).

The reconstruction of the Pliny manuscript by various scholars appears particularly weak as far as Book XXXIII is concerned. Although it has been a basic reference for historians of metallurgy for many. centuries, it still contains ambiguities that have been clarified only in part by emendations of the text which have been made from time to time and which have been mostly of a philological nature. These ambiguities are usually mentioned by experts who quote
Pliny in discussions of the extent of the metallurgical and chemical knowledge of the Romans.

The passages (5) devoted by Pliny to gilding read:

'20. The regular way to gild copper would be to use natural or at all events artificial quicksilver, concerning which a method of adulteration has been devised, as we shall relate in describing the nature of those substances. The copper is first subjected to the violence of fire; then, when it is red hot, it is quenched with a mixture of brine, vinegar, and alum, and afterwards put to a test, its brilliance of colour showing whether it has been sufficiently heated; then it is again dried in the fire, so that, after a thorough polishing with a mixture of pumice and alum, it is able to take the gold-leaf laid on with quicksilver.'

'32. . Consequently when also things made of copper are gilded, a coat of quicksilver is applied underneath the gold leaf and keeps it in its place with the greatest tenacity: but if the goldleaf is put on in one layer or is very thin it reveals the quicksilver by its pale colour. Consequently persons intending this fraud adulterated the quicksilver used for this purpose with white of egg; and later they falsified also hydrargyrum or artificial quicksilver, which we shall speak about in its proper place. Otherwise quicksilver is not to be found in any large quantity.'

'42. At the present time silver is almost the only substance that is gilded with artificial quicksilver, though really a similar method ought to be used in coating copper. But the same fraudulence which is so extremely ingenious in every department of life has devised an inferior material, as we have shown.'

The hitherto generally accepted interpretation of these extracts, often supported by quotations from Vitruvius (6), is that Pliny is referring to the gilding technique which we call hot mercury-gilding or firegilding. This implies that both Pliny and Vitruvius are thought to have omitted to mention the final stage of the fire-gilding process which consists of heating the piece in order to evaporate the mercury.

A few writers are more cautious and have an open mind in this respect. Moran (7), for instance, states 
'But whether or not Vitruvius was definitely referring to the fire-gilding process we cannot say. And Pliny, though mentioning mercury as being used in the gilding of copper, seems definitely not to be referring to the fire-gilding process in the ordinary meaning of that phrase.'

\section{A New Interpretation of Pliny}

Careful reading of what is reported by Pliny and comparison with descriptions of the common firegilding technique, show that apart from the ambiguity of some words, two substantially different processes are involved. Fire-gilding has been described by many authors but Cellini's text (8) is the most famous of those written by craftsmen and more recent authors may have been influenced by it.

In Cellini's description of gilding, the layer of gold is formed in situ. He uses gold leaf but only because it amalgamates rapidly with the mercury inside the mortar. The gold/mercury ratio in the amalgam varies between fairly wide limits (9). The final composition is reached step by step and is based on the artist's personal experience, taking into account both the size of the artefact and the desired thickness of gilding. Further coatings of amalgam can be applied if the initial result is not satisfactory. The final stage of heating in the fire requires continuous supervision of the piece to maintain the distribution of the amalgam on its surface and is an operation basic to the process since it is indispensable in order to form the gold layer.

Pliny, on the other hand, refers to gold leaf applied directly to the substrate. If this is interpreted exactly as he describes it, the following operations are involved:

(1) Mercury is rubbed on the surface of the copper substrate when it is cold. Some copper dissolves in the mercury and forms a very thin layer of copper-mercury amalgam. At room temperature, copper does not become soft in the presence of mercury $(10,11)$.

(2) Any excess mercury is mechanically removed. This operation leaves the surface of the object shining and smooth as a mirror.

(3) Gold leaf is then pressed upon the surface. It absorbs a little mercury from the copper but does not soften and does not form a conventional amalgam. Even if the gold leaf absorbs all the mercury from the copper-mercury amalgam, it does not disintegrate but keeps its original leaf form and bonds very firmly to the substrate.

This method, best referred to as cold mercurygilding (12), does not appear to require special operator skills since the amount of mercury involved is independent of the procedure followed by the craftsman and the mechanics of the operation are defined exclusively by the solubility of copper in mercury. An additional advantage is that the consumption of mercury is minimal. Mercury is mainly lost by diffusion through the gold layer. This is inevitably a slow process (several weeks) and bears no comparison with the speed at which the mercury is driven off during a normal fire-gilding operation when the gold is applied in the form of a true amalgam. A significant aspect of the use of mercury is emphasised by Pliny in his comment that 'if the gold leaf is put on in one layer or is very thin it reveals the quick-silver by its pale colour'. Thus, the 'pallor' indicated the presence of mercury.

\section{The Fraudulent Method of Gilding}

Pliny himself seems to confirm what is said here of this cold mercury process in the passages that describe a fraudulent method of gilding.

The text implies that the fraud refers to the mercury and not to the gold. In Pliny's time mercury, in both the native and the artificial or purified form, was relatively expensive and scarce. On the other hand, the word 'recte' used by Vitruvius, as well as the 'legitimus erat' of Pliny, mean that only gilding carried out by mercury was considered genuine. According to Pliny a particular type of pallor appeared to be the only feature that objectively indicated - and in some way proved to the purchaser - the use of expensive mercury for gilding. If the pallor was removed by heating, as happens in the final stage of normal firegilding, Pliny's mention of pallor in the context of fraud would have no sense. Therefore, the fraud appears to consist in gilding by another method and in imitating in some manner the pallor resulting from the use of mercury. This, Pliny tells us, was achieved by using the white of an egg (or glair) and laboratory trials have shown that the effect thus obtained closely resembles that from cold mercury-gilding (13).

In these experiments, glair was smeared onto an object which had been previously hot gilded without mercury and any excess was removed. When the temperature of the metal was raised to around $100^{\circ} \mathrm{C}$ the gold surface became pale, changing to a finish very similar to that of gold contaminated by mercury. The similarity extended to both the colour and the surface pattern. Indeed, two authors, Pancirollus (14) and Zasius (15) have interpreted the fraud described by Pliny as using egg white to make it appear as if mercury had been used in the gilding process. This was done by mechanically cladding gold leaf on to the hot substrate after suitable preparation and then applying a coat of egg white.

The use of egg white on top of the gold has a further important property that made it effective as a fraudulent substitute for mercury. The pallor due to mercury fades after some time as it evaporates. Likewise, the pallor obtained using egg white is not permanent. After some days, glair undergoes biochemical degradation and disappears. This behaviour was an assurance to the goldsmith that his 


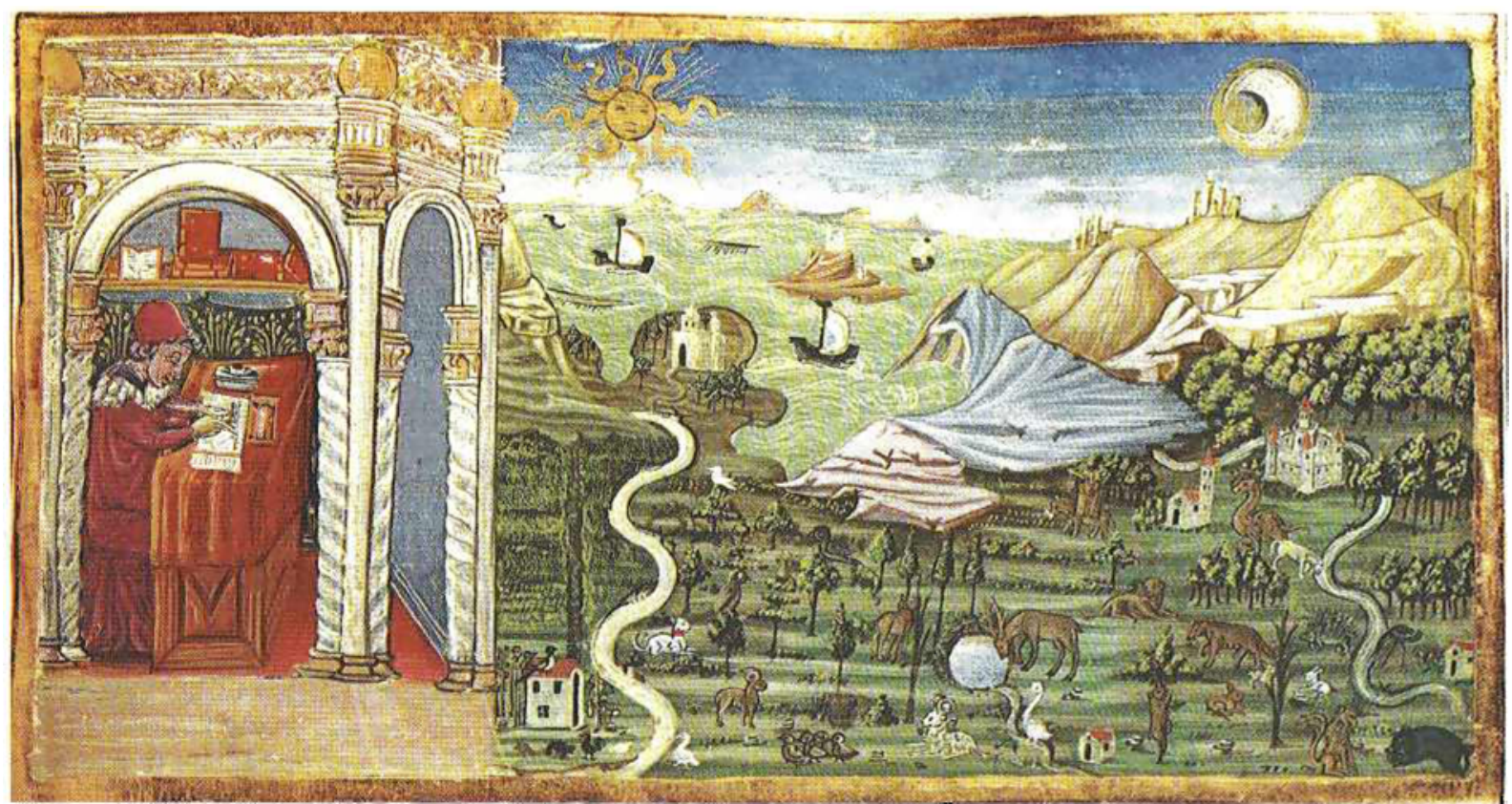

Gaius Plinius Secundus

23 to 79 A.D.
Pliny the EIder, as he is more generally known, compiled the first great technical encyclopaedia, 'Naturalis Historia', its thirty seven books containing an enormous collection of information. Although not accurate in all details it is an important source of our knowledge of Roman technology and gives one of the first references to gilding. This painting of Pliny in his study is from a XVth century manuscript copy of his 'Natural History' in the British Library

Harley MS. 2677, f.1. Reproduced by permission of the British Library fraudulent practice would not be detected and to the customer that he had bought a 'correctly' gilded piece.

A complete analysis reconciling Pliny's existing text with the new interpretation of his manuscript presented here, will be published elsewhere (28) and will take account of philological comments by Professor Silvio Ferri.

\section{Laboratory Experiments}

The conclusions drawn from the detailed study of Pliny's text have been substantiated with some additional information of a more objective character. Dr. L. Rigosi of the Physical Institute of Ferrara University has established that cold mercury-gilding of copper can be performed in the laboratory without any problem. Spreading of mercury on the copper surface, polishing the surface until it has a mirrorlike finish and applying gold leaf are simple and reproducible operations. The gold layer remains intact and the mercury which contaminates its surface imparts to it a characteristic pallor. This gilding operation could be carried out on 7 per cent tinbronze as well as on copper. Examination of the interface between the gold and the substrate by electron probe microanalysis showed that the boundary itself was very sharp, both with copper and bronze.

A most interesting aspect of cold mercury-gilding concerns the finishing of the gilt surface. While gilding applied on pure copper can be very easily finished with a burnishing tool, this is not the case with a bronze substrate. On the latter alloy, burnishing destroys the gilded layer. This behaviour appears to support the hypothesis presented in the outset of this paper concerning the difficulties encountered in gilding bronze as opposed to pure copper. Alloying of gold with tin easily takes place in the presence of mercury at the gold-bronze interface (mercury amalgamates well with tin) and the brittleness of the products must be the cause of the observed fragility of the gild (16). Even in hot cladding, where mercury is not used, tin can migrate from the bronze into the gold leaf at high temperature. Mr. E. Canal, an expert in archaeology who has, a workshop in Venice which reproduces artefacts by ancient techniques has kindly carried out the cladding of both copper and bronze with gold leaf. As might be expected in terms of the interpretations above, cladding, in which the use of the burnishing tool is of fundamental inportance, gave good results on pure copper but was impossible on bronze (17).

\section{The Necessity to Use Pure Copper}

It is of interest to conclude this contribution by presenting a few points selected from a large series of references. These throw some light on the question of the composition of the alloy for gilding and they reinforce Craddock's suggestions.

The association of gilding with pure copper in ancient artefacts from the classical period is confirmed by the nature of the metal objects found on Roman 
ships recovered from the bottom of Lake Nemi in 1928. A list of these artefacts (18) classifies those of interest in the present connection as either of 'pure copper' or of 'bronze'. All the pure copper artefacts are reported to be gilt while of the bronze items only one is described as gilt.

The fragility of gold when contaminated by tin and lead seems to have been well known in the past and is mentioned in some old encyclopaedias. Vannuccio Biringuccio in particular writes about the effect on gold of contamination by other metals during gilding (19). D'Arcet's work (20) on fire-gilding of bronze is generally considered one of the most important references on this subject written in the more recent past. The goldsmiths he consulted in his survey of the gilding of different substrates told him that the less tin and lead contained in a copper alloy, the better was the gilding. Another excellent account of the metallurgical aspects of the gilding technique is to be found in Bonazzi's 'Guide to the Goldsmiths' (21). His technical and chemical terminology is accurate. $\mathrm{He}$ describes the 'classical fire-gilding technique' and the preparation of the bronze or brass substrate to be gilt. The piece had to be previously put on the fire 'with its surface covered all over by coal' or another fuel 'that burns well producing a fire more uniform and less intense than coal'. This procedure was justified by the goldsmiths, 'according to their own understanding of the gilding', as having the purpose of degreasing the metal surface. Bonazzi then says:
'They attribute the beautiful colour of the gilding to this perfect cleaning. D'Arcet thinks, and he is right, that this operation results in a burning-out of part of the zinc at the surface of the brass, so that the surface becomes more or less pure copper. It is for this reason that it better retains the gilding and acquires a brilliant colour.' $(22,23)$.

\section{Conclusion}

It is reasonable to assume that pure copper substrates were used for gilded artefacts of the classical period not by chance but for technical reasons. The cold mercury-gilding technique, which this paper suggests was the mercury-gilding method known at the time, was not a flexible one and it was because it was most effective on copper substrates that these were used when gilded artefacts were being made. If gilding of an object was not envisaged, it could be made from a copper-tin-lead alloy which had better castability than copper. In that case, however, it could not be cold mercury-gilded at a later date.

An example which appears to support this view can be indirectly drawn from Pliny. Nero wanted a Greek bronze statue of the infant Alexander the Great to be gilded. The gold was later removed and Pliny records that in that condition the statue was considered yet more valuable, even though still retaining scars from the work done on it and incisions in which the gold had been fastened.' (24). This has been interpreted by Falconet (25) and Blümner (26) as a reference to gilding 'à l'hache'' where gold foil (rather than leaf) was mechanically keyed by hammering onto the substrate in which deep cuts had been made with a sharp tool (27). Such mechanical gilding, for which there are several techniques, could be used when the substrate was not susceptible to cold mercury-gilding because of its metallurgical character.

Fire-gilding was only developed at a later time. Although, like cold mercury-gilding, the process presents difficulties when applied to copper alloys containing tin and

This illumination showing a goldsmith's workshop is from a XIVth century Latin manuscript of Pliny's 'Natural History'. The manuscript is kept at the Marciana Library in Venice 
lead, these were overcome by the skills and resourcefulness of ancient craftsmen and many hot mercury-gilded works of arts made from a large variety of alloys have survived to this day.

\section{Acknowledgements}

The author is grateful for the contributions given to this research by Dr. L. Rigosi and Mr. E. Canal, which were of fundamental importance. Dr. Rigosi discovered the Pancirollus reference. I thank him also for helpful discussions on the results of the cold mercury-gilding laboratory tests. Prof. G. Pugliesi Carratelli kindly assisted me in interpreting some of the morc obscure passages of Pliny and I thank him also for drawing the attention of Prof. Silvio Ferri to this research. Mr. W. A. Oddy and Dr. P. Craddock helped me in the earlier phase of this work by discussing some of their views on the entire matter. Thanks to the invaluable help of the former the English text was given additional clarification and a much more satisfactory form.

\section{References and Notes}

1 O. Vittori and A. Mestitz, Burlington Mag., 1975, CXVII, 132-139

2 P. Craddock, F. Archeol. Sci., 1977, 4, 103-123

3 P. A. Lins and W. A. Oddy, 7. Archeol. Sci., 1975, 2, 365-373 M. Picon, J. Condamin and S. Boucher, Gallia, 1966, XXIV, 189-215; 1967, XXV, 153-168

W. A. Oddy, T. G. Padley and N. D. Meeks, in 'Proceedings of the 18th International Symposium on Archeometry', Rheinisches Landesmuseum, Bonn, 1978

$4 \mathrm{H}$. Blümner, 'Technologie und Terminologie der Gewerbe und Künste by Griechen und Römern', Band III, Leipzig, 1884

E. D. von Lippman, Mitt. Osterlande, 1892, N.F.5, 370-418; 'Abhandlungen und Vorträge zur Geschichte der Naturwissenschaften', Leipzig, 1906, p. 1.46

S. Ferri, 'Plinio il Vecchio, Storia delle Arte Antiche', Erma, Rome, 1946

K. C. Bailey, 'The Elder Pliny's Chapters on Chemical Subjects', Arnold, London, 1929-1932; Hermathena, 1926, XLIV, 73-83

M. Berthelot, 'Archéologie et Histoire des Sciences', Steinheil, Paris, 1906

J. Beckmann 'A Concise History of Ancient Institutions, Inventions and Discoveries', G. \& W. B. Whittaker, London, 1823

T. T. Read, Archeol. Inst. Am., 1934, X, 382-389

E. Sellers, "The Elder Pliny's Chapters on the History of Arts', London, 1896

Bibliographies on Pliny's 'Natural History' are compiled by M. Marouzeau and regularly published in Année Philologique

5 Pliny, 'Natural History', translation by H. Rackham, Loeb Classical Library, London, 1952

6 Vitruvius, 'De Architectura', translation by M. H. Morgan, Harvard Univ. Press, 1926, Book VII, Chap. 8, p. 215, writes: 'Quicksilver is useful for many purposes. For instance, neither silver nor copper can be properly gilded without it'.

7 S. F. Moran, Artibus Asiae, 1964, XXXI, (1), 55

G. Winkelman, 'Storia delle Arti Presso gli Antichi', translation by C. Fea, Stamperia Pagliarini, Rome, 1783 H. Blümner, op. cit., p. 314

8 B. Cellini, 'I Trattati dell 'Oreficeria e della Scultura', Florence, 1568

9 M. d'Arcet, 'Mêmoire sur l'Art de Dorer le Bronze au Moyen de l'Amalgame d'Or et de Mercure', Imprimerie Vve Agasse, Paris, 1818

'Enciclopedia della Chimica Guareschi', University of Turin, Turin, 1910 , p. 438.

A. Jakob in Dorenberg and Saglio, 'Dictionnaire des Antiquités', p. 311, suggests that both the substrate and the gold leaf could be impregnated with mercury before gilding. However, gold leaf disintegrates in contact with mercury.

10 W. J. Humphreys, f. Chem. Soc. Trans., 1896, 69, 243 \& 1679

11 P. Rayson and G. Calvert, 7 . Inst. Met., 1958-1959, 87, (3), 88

$12 \mathrm{~B}$. Bearzi, private communication, independently suggests that the Ancients could use a cold-mercury gilding technique.

$13 \mathrm{H}$. Blümner, op. cit., p. 314, suggests strangely that the pallor could be attributed to the effect of the substrate!

14 Pancirollus Guidus, 'Rerum Memorabilium Sive Deperditorum Libri Commentariis Illustrati', Frankfurt, 1660

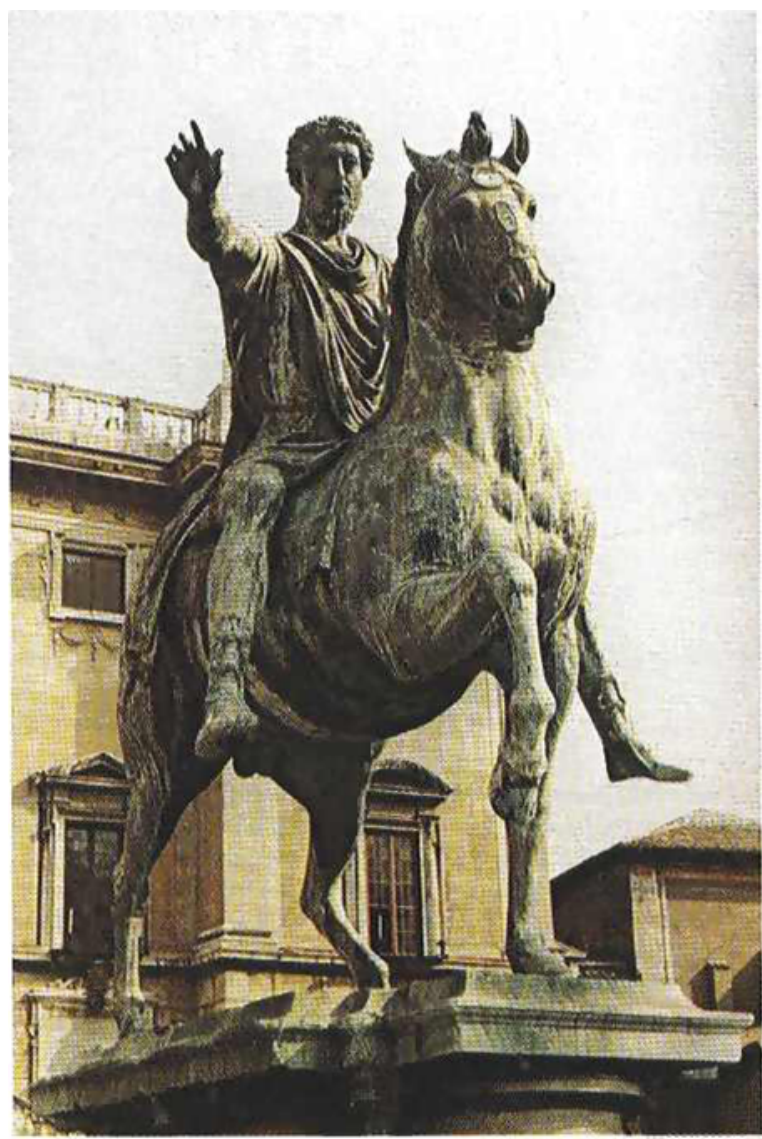

Very few gilded bronze statues survive from Roman times, but the famous equestrian statue of Marcus Aurelius on the Capitol in Rome must have been typical of many. Was this gilded by the normal process, or by the method described by Pliny which is re-interpreted in this article?

15 Zazius, 'De Obligationibus', Padua, 1420, p. 518

16 'Encicl. Chim. Guareschi', op. cit., p. 428

$17 \mathrm{E}$. Canal, private communication, reports in substance that pure commercial copper is the 'easier' metal to gild by hot cladding. Some adhesion of the gold leaf takes place at 100 to $120^{\circ} \mathrm{C}$. Bonding is good at 250 to $280^{\circ} \mathrm{C}$ and optimal conditions are upwards from 350 to $380^{\circ} \mathrm{C}$. Serious difficulties are encountered with brass or bronze substrates and even at temperatures up to $500^{\circ} \mathrm{C}$ the gold leaf is not retained by the alloy. The gild is often scratched and detached during burnishing, even if this operation is carried out with great care.

18 G. Ucelli, 'Le Navi di Nemi', Libreria dello Stato, Rome, 1940

19 V. Biringuccio, 'Della Pirotechnia', Book X, Venice, 1540, p. 280-281

20 M. d'Arcet, op. cit.

21 D. Bonazzi, 'Guida per i Doratori', Bologna, 1811

22 J. G. Hawthorne and C. S. Smith, 'On Divers Arts: The Treatise of Theophilus', Chicago, 1963, p. 125, also gives an account of the purification of copper with fine ashes and coal.

$23 \mathrm{G}$. Winkelman, op. cit., introd. to Book VII, Chap. 2, confirms that the Ancients preferred copper to bronze as a substrate for gilding, although his technical descriptions are not very

precise.
L. Bossi, 'Opuscoli Scelti sulle Scienze e sulle Arti', Book XV, p. 217 , says ". . that whatever kind of fire-refining was used by the Ancients, it was applied only to those pieces that had to be gilded...' Bossi's expertise on ancient techniques is acknowledged by several authors of the XVIIIth century.

24 Pliny, op. cit., Book XXXIV, Chap. 19

25 Pliny, 'Natural History', translation by E. Falconet, 2nd Edition, Vol. 2, Amsterdam, 1772, p. 8

$26 \mathrm{H}$, Blümner, op. cit., p. 311

27 D. Diderot and J. d'Alembert, 'La Grande Encyclopédie', Paris, 1751-1780, under the item dorure

28 O. Vittori, Riv. Archeol., Univ. Venezia, 1978, II, in press 